\title{
Advice for Clinician Educators
}

\author{
Douglas J. Gelb, MD, PhD
}

$\mathrm{N}$ ot long ago, the idea of making education the focus of an academic career in neurology would have been heretical. Many of us were taught that to be an academic neurologist, anything less than a triple threat-a master clinician, teacher, and researcher-was unacceptable.

For a variety of reasons, the triple threat is no longer maintained as a universal ideal, and academic neurologists whose focus is education (typically referred to as clinician-educators) have gained respectability. This career path remains a little out of the mainstream, however, and it is less standardized than the traditional academic path focusing on research. Educational productivity is harder to measure than research and clinical productivity. The metrics by which research is judged-publications, citations, and external supportdo not apply to teaching. Unlike clinical activity and research activity, teaching activity is divorced from a direct revenue stream in most academic medical centers.

Different medical centers and different departments have approached these issues in various ways, so it is difficult to offer specific career advice that would be pertinent in all settings, but some broad principles apply. In this article, I offer some general advice and observations for neurologists hoping to develop a career focusing on education.

\section{Getting Started}

You are unlikely to be asked to serve as a residency program director, clerkship director, or preclinical neuroscience course director right at the outset of your career, and that is probably a good thing. When you are just starting out, your main goal should be to adapt your teaching style to your new role as a faculty member and to refine your ability to teach trainees while delivering excellent and efficient patient care. Once you have had some time to establish yourself and to get acclimated to the institution, the culture, and the people, you can start looking for other educational roles (Table 1).

\section{Establishing a Direction}

When you first start out as a faculty member, it is fine to request certain educational responsibilities and to state your preferences (eg, resident teaching rather than medical student teaching; small group rather than lecture), but you may have to take what you get; you do not want to appear too picky or too negative when educational or administrative responsibilities are offered to you. Assuming that you perform well, you will almost certainly be offered additional responsibilities, and eventually you will accumulate so many responsibilities that you will be able to engage in selective pruning.

Reflect on what types of educational activities you find most rewarding and what direction you would like your career to take. Retain those responsibilities and work to expand them, and turn over to others the duties you find less desirable. If you would like to be considered for specific positions such as residency program director or clerkship director, inform your chair and the people who currently hold those positions. Make it clear that you are not looking to take away anyone else's job, but that you would like to be considered when opportunities arise. In this way, you can gradually mold your job description into something approaching your ideal job, without antagonizing your chair or colleagues.

\section{Achieving Prominence}

At most medical schools, academic promotion requires demonstration of regional or national prominence. Traditional intramural teaching activities do not usually result in recognition outside your own institution, so if promotion is important to you, you will probably need to expand the scope of your activities. The options can be grouped into 2 main categories: participation in extramural organizations and dissemination of scholarly work. 


\section{TABLE 1. Possible Roles for New Junior Faculty Interested in Medical Education}

Developing a medical school elective

Developing a medical school experience-eg, an OSCE, a problem-based learning module, a neurological examination sequence in a physical examination course, a simulated patient lumbar puncture exercise, or a direct observation experience

Advising your institution's SIGN

Developing or coordinating your department's CSEs-the exercises within residency training that have replaced the oral board examination

Developing or coordinating a residency experience-eg, a rehabilitation rotation or a research experience

Organizing a departmental lecture series

Becoming a member of a departmental committee-eg, neurology clerkship committee, residency selection committee, or residency program evaluation committee

Becoming a member of a medical school committee-eg, curriculum committee or admissions committee

Giving lectures to other departments within the institution

Giving lectures at other local institutions

Teaching in or organizing local CME courses

$\mathrm{CME}=$ continuing medical education; $\mathrm{CSE}=$ clinical skills evaluation; OSCE $=$ objective structured clinical examination;

SIGN $=$ student interest group in neurology.

\section{Extramural Responsibilities}

It may seem daunting to seek a leadership role at a national level, but opportunities are plentiful, perhaps because these jobs involve extra work for no extra pay. For the same reason, if you are willing to put a little effort into this type of activity, the payoff can be considerable. Often, these groups meet on an annual or semiannual basis, and the people who attend these meetings develop all sorts of ambitious and creative plans when they are together, only to find that when they get back home all of their local responsibilities and deadlines preempt the work they had planned to do for the national group. If you actually follow through on the commitments you make to a national group, you will immediately stand out from the crowd, and you can quickly rise to positions of increasing responsibility and importance at a national level. Table 2 lists national organizations active in neurologic education.

Extramural teaching is another way to achieve regional and national prominence. As you become more established clinically, you are likely to receive invitations to speak at nearby hospitals or to address local physicians' associations, patient support groups, and other organizations. Additional teaching opportunities may arise through the connections you establish in regional and national societies (both educational and clinical). When you participate in this type of teaching activity, try to determine whether the sponsoring group routinely collects evaluations from audience members, and if so, request a copy of the results. This will not only help you improve your teaching, but it will be useful documentation of teaching effectiveness when you seek promotion.

Many pharmaceutical companies invite academic neurologists to serve on their speaker panels. Such invitations may be flattering, especially early in your career, and the prospect of additional revenue can also be tempting. Approach these invitations cautiously. They can take time away from other activities that are viewed more favorably by promotions committees. If you accept too many industry-sponsored speaking engagements, you may develop a reputation as a "gun for hire." At the very least, if you serve on a company's speaker panel, you will have to disclose this whenever you lecture or write on any subject related to that company's products, which could make your comments appear less objective.

\section{Scholarly Products}

For faculty members focusing on education, most academic medical centers define scholarly productivity much more broadly than just the number of publications in peer-reviewed journals. High-quality educational materials, such as medical school course syllabi or computer tutorials, may require just as much thought and creativity as traditional academic articles. They are generally not subject to peer review, however. One way to achieve peer-reviewed status for nontraditional educational materials is to submit them to the Association of American Medical Colleges (AAMC) MedEdPortal (https://www. 


\section{TABLE 2. National Opportunities in Neurology Education}

ANA Education Committee
AAN Education Committee

Undergraduate Education Subcommittee

Graduate Education Subcommittee

Education Research Subcommittee

Examination Subcommittee

Distance Learning Subcommittee

AAN Meeting Management Committee

AAN consortia

Consortium of Neurology Clerkship Directors

Consortium of Neurology Program Directors

AAN A. B. Baker Section of Neurologic Educators

ABPN

NBME

AAMC

AAMC $=$ Association of American Medical Colleges; AAN = American Academy of Neurology; ABPN = American

Board of Psychiatry and Neurology; ANA = American

Neurological Association; NBME = National Board of

Medical Examiners.

mededportal.org). This is a useful resource to know about even if you do not submit anything to it yourself.

\section{Promotion and Tenure}

Clinician-educators are eligible for tenure at some medical schools and not others, but the distinction has minimal practical implications. Most academic medical centers require faculty members to generate enough revenue to support their own salary, regardless of tenure status. At many medical schools, junior faculty choosing a clinician-educator path have more job security than those choosing a traditional research path, because academic departments generally do not impose a promotion "clock" on clinician-educators. You need not pursue promotion if it is not a high priority for you; as long as you are providing sufficiently valuable service to the department, your job is safe. Recognize that your opinions about promotion could change in the future, however. Be sure you are familiar with the procedures and criteria for promotion in your department, so that when and if you decide that you are interested in promotion, you will be ready.

Many institutions supplement the traditional curriculum vitae with an educator portfolio or teaching portfolio, which provides more details about the individual's educational activities, often including narrative comments intended to put those activities in context and measures of teaching effectiveness (such as numerical scores and comments from students' evaluations). Find out whether your institution uses a specific format for educator portfolios; if it does not, the following website provides links to a number of websites offering further information: http://libraries.rbhs.rutgers.edu/rwjlbweb/meg/cte/career_ development/careerdevelopment_developing_maintain_ teaching_portfolio.html

\section{Economic Considerations}

Some academic medical centers and departments have introduced accounting systems and formulas intended to distribute educational funds to individual faculty members based on the nature and extent of their educational activities. In many academic medical centers, however, funds from various sources get thrown into a single pot, and deans and department chairs distribute those funds as they see fit. This distribution often emphasizes faculty who are perceived to be contributing to the department's financial well-being by generating clinical revenue or grant support. Faculty who are heavily involved in education may need to remind their colleagues and department chairs that by doing a disproportionate share of the department's teaching and educational administration, they contribute to the department's mission and free up their colleagues to engage in other activities that generate revenue for the department.

Funding for educational research exists, but it is limited. Your own institution may offer small grants. The American Academy of Neurology (AAN) offers 2 to 4 grants per year of up to $\$ 10,000$ each for research projects in neurologic education. Private foundation grants can also be obtained.

\section{Educational Research}

Opportunities for you to publish original clinical or basic science research will generally be linked to your clinical activities and collaborations. Your educational activities can also serve as the basis for research. Most current educational practices are based on tradition, intuition, and convenience, rather than evidence, and legitimate questions abound. In many cases, the trainees themselves will raise these questions (often in the form of complaints). What are the best venues for clinical teaching ("Will my grade suffer if I am assigned to a certain site")? Who should be doing the teaching ("Will my grade suffer because I worked mainly with residents, not faculty")? In other cases, questions arise when considering changes to the current system, for whatever reason. Develop the habit of asking yourself: "How would I go about trying 
to answer this question, if I wanted to pursue it further?" You may realize that you have already collected the necessary data, or that it would be a simple matter to do so. For example, if you have been keeping track of student examination scores in a way that allows you to sort students by clerkship site, you can easily determine whether there is a correlation. Before going to the trouble, you should also ask yourself whether the question is worth answering. Will the answer to the question affect the way you teach? Could the answer make you challenge some of the assumptions under which you operate? Might there be implications for others outside your institution? For example, if there really is a correlation between examination scores and clerkship sites, it would probably be important to know about it, both for the sake of treating your students fairly, and with respect to the broader question of how much the variability of students' clinical experience affects their education.

If you are considering embarking on education research, do your homework. Look to see what work has already been done; a vast literature of education research exists, although most physicians have little exposure to it. Also, recognize that randomized controlled trials (RCTs) in medical education are difficult. If you want to conduct an RCT involving neurology residents, for example, and your program admits only 4 residents per class, it could take you years to amass enough study subjects to achieve statistical significance. You can enroll more subjects by cooperating with other residency programs, but this introduces additional variables into the study (and a host of administrative considerations). Studies involving medical students are more likely to achieve the numbers required for statistical significance, but costs may be prohibitive. For a study to be truly random, the experimental group and the control group should be concurrent, which means that the medical school will have to administer two different educational methods simultaneously (each to half the class). This could place unrealistic demands on faculty time and other resources. A lack of equipoise can also be a barrier to RCTs in medical education; almost anyone who has ever gone to school has strong opinions about which educational methods work and which do not, and will have qualms about randomly assigning some students to a group that may be taught using methods perceived to be inferior. These obstacles are no excuse for omitting a control group, however, or for using a suboptimal control. For example, if you develop a new educational tool and want to demonstrate that it is effective, your control group should be students who were taught the same material using traditional methods (rather than students who were not taught the material at all).
Outcome measures are also a challenge in medical education research. Ultimately, the outcome measure of interest is the quality of patient care that trainees provide once they are treating patients independently (ie, 1 or more years after completing their training). Ideally, this would be assessed by surreptitiously observing their interactions with real patients, or at least with simulated patients. The practical barriers to this type of follow-up are enormous, however. Even if the majority of trainees could be tracked down and assessed in some reliable fashion, it would be difficult to draw any conclusions about the effectiveness of specific educational methods, because so many confounding variables would have been interposed in the years since their training. As a result, most educational research uses surrogate outcome measures, such as examination results or trainees' responses to questionnaires.

\section{Clinician Aspect of Clinician-Educator}

Every clinician-educator's job description is different. The relative proportion of clinical activity and educational activity will vary from institution to institution, across departments within an institution, from one person to another within a department, and from one time period to another within an individual's career. I have focused here on the educational activities of clinician-educators, but analogous points apply to the clinical activities. As discussed above, you can lecture to local groups, at nearby hospitals, at other medical schools, and in continuing medical education courses. You can accrue regional and national recognition by taking on responsibilities within your department (eg, head of a laboratory, the outpatient clinic, or a subspecialty program), your medical school, or local or national professional societies (including the subspecialty sections of the AAN). Depending on your clinical role, you may have opportunities to participate in clinical research or write reviews or book chapters on clinical topics. Once again, as you become better known at your institution and beyond and you are offered more new responsibilities, you should approach them in a deliberate and discriminating manner, accepting those that move your career in the direction you want and declining those that do not, no matter how flattering they might be.

\section{General Neurologist or Subspecialist}

As a clinician-educator, you can choose to be a general neurologist, a subspecialist, or a hybrid of the two. A subspecialty niche can make it easier to develop and maintain expertise, it can provide an obvious unifying theme for your educational endeavors, and it can 
enhance your opportunities to engage in the kinds of activities discussed in the previous paragraph (directing clinical programs or fellowships, running a weekly departmental conference, delivering extramural lectures, participating in research, writing reviews, and so forth). Although these are strong incentives to subspecialize, there are equally compelling reasons to remain a general neurologist. Local hospitals and other groups are often more interested in hearing lectures that are surveys or reviews than lectures on subspecialty topics. Medical students and even residents often prefer lecturers with a broad perspective, as opposed to those who spend a disproportionate amount of time focusing on their field of subspecialty interest. More advanced residents and fellows certainly benefit by managing patients under the supervision of subspecialists who have expertise in those patients' conditions, but even in that context generalists can play a critical role. Many patients referred to subspecialists have problems beyond the scope of the available clinical evidence, and subspecialists must manage them based on a combination of their knowledge of pathophysiology and their clinical experience. For a variety of reasons, the subspecialists working together in one department will usually manage these patients in a fairly consistent way from one instance to another. It can be difficult for trainees working with those subspecialists to distinguish the management practices that are evidencebased and widely accepted as standard of care from those that reflect the judgment and experience of the individual subspecialists in their department. By challenging trainees to defend the approach they have learned from subspecialists ("How will an MRA change our management of this patient?" or "What makes you think physical therapy will help that patient?"), and by refusing to accept the answer "I don't know, but that's what Dr. X always does," generalists can help ensure that the trainees understand the foundations of their management decisions. In principle, subspecialists can also challenge trainees in this way, but generalists' status as outsiders makes it easier and more natural for them to maintain a critical perspective.

From a practical standpoint, subspecialists often offer clinical skills and services not widely available in the community, attracting patient referrals, whereas outside neurologists might see no need to refer to a generalist. Nonetheless, many patients referred to academic neurology departments have no established diagnoses or even diagnostic categories, making general neurologists the ideal candidates to evaluate them.

In short, both subspecialists and generalists make important contributions to academic neurology departments, and there are a variety of career opportunities for both. If you decide to subspecialize, you should do so because of your interest in the subspecialty, not based on the perceived opportunities for career development.

\section{Resources}

Although you may sometimes feel that as a clinicianeducator you are blazing an entirely new path, take heart-others have gone before you. When you confront a new question or task, you would do well to see if there are already tools available to help. ${ }^{1-7}$ If you ask around, you may find that there are people at your institution with training, experience, and resources you did not even realize were available. If your medical center is affiliated with a university, you could also seek advice from the school of education. Many of the American Neurological Association (ANA) and AAN education-related groups listed in Table 2 are excellent venues for establishing connections with neurologic clinician-educators across the country. In particular, if you become a director of a neurology residency program, you should promptly join the Consortium of Neurology Program Directors; clerkship directors should likewise join the Consortium of Neurology Clerkship Directors.

Some medical schools offer short courses (anywhere from a couple of hours to a couple of days) on topics of interest to clinician-educators. Some medical schools offer more extensive programs (eg, 1 half-day each week for a number of months) surveying relevant topics in medical education. The ANA and AAN both offer courses related to medical education. The AAMC offers workshops in medical education research leading to a Medical Education Research Certificate (https://www.aamc.org/members/gea/65490/merc/). The Center for Teaching Excellence at the University of Medicine and Dentistry of New Jersey has developed a useful directory of Internet resources (http://cte.umdnj. edu/career_development/index.cfm), which includes a partial list of academic medical centers with programs in medical education; some of these institutions have faculty development courses open to faculty from other centers.

\section{Challenges and Opportunities}

I have offered advice that pertains to the existing system of medical education, but that system will undoubtedly change dramatically in coming years. The explosion of biomedical knowledge makes it impossible for any individual's brain to contain all the knowledge necessary to be an effective clinician, but fortunately 
(and not entirely coincidentally), technological advances have made it possible to access vast quantities of information rapidly. We have not yet adapted our educational practices accordingly. We need to determine what core principles and factual material students must master in order to use databases efficiently and intelligently. We also need to reconsider our teaching and testing methodology. If trainees will be practicing in settings where they always have access to large databases, should all examinations be open book? Changes in the health care system and the accrediting bodies for medical schools and graduate medical education are imposing increasing requirements for standardization and accountability, leading to a proliferation of templates and checklists. How do we teach our trainees to use those instruments and still think independently and rigorously? The ascendance of competency-based education also compels us to think creatively about what trainees need to know, and when. All of these developments are bound to result in major changes in what and how we teach at all levels, from medical school through postgraduate continuing medical education. The challenges are great, but for clinician-educators with open minds and a willingness to take a fresh approach, the opportunities are limitless.

\section{Potential Conflicts of Interest}

Nothing to report.

\section{References}

1. Pangaro L, Fincher RM, Bachicha J, et al. Expectations of and for clerkship directors: a collaborative statement from the Alliance for Clinical Education. Teach Learn Med 2003;15:217-222.

2. Geraci SA, Babbott SF, Hollander H, et al. AAIM report on master teachers and clinician educators part 1: needs and skills. Am J Med 2010;123:769-773.

3. Geraci SA, Kovach RA, Babbott SF, et al. AAIM report on master teachers and clinician educators part 2: faculty development and training. Am J Med 2010;123:869.e6-872.e6.

4. Geraci SA, Devine DR, Babbott SF, et al. AAIM report on master teachers and clinician educators part 3: finances and resourcing. Am J Med 2010;123:963-967.

5. Geraci SA, Hollander H, Babbott SF, et al. AAIM report on master teachers and clinician educators part 4: faculty role and scholarship. Am J Med 2010;123:1065-1069.

6. Geraci SA, Buranosky R, Babbott SF, et al. AAIM report on master teachers and clinician educators part 5: academic documentation and tenure. Am J Med 2010;123:1151.e8-1154.e8.

7. Morgenstern BZ, ed. Guidebook for clerkship directors. 4th ed Syracuse, NY: Gegensatz Press, 2012.

DOI: 10.1002/ana.24154 